\title{
0 papel da auditoria interna na promoção da accountability nas Instituições de Ensino Superior
}

\author{
Anabela dos Reis Fonseca ${ }^{1}$ \\ Susana Jorge 23 \\ Caio Nascimento ${ }^{4}$ \\ 1 Universidade de Coimbra, Coimbra — Portugal \\ 2 Universidade de Coimbra / Faculdade de Economia, Coimbra — Portugal \\ 3 Universidade do Minho / Centro de Investigação em Ciência Política, Braga — Portugal \\ ${ }^{4}$ Instituto Federal de Educação, Ciência e Tecnologia de Roraima, Boa Vista / RR — Brasil
}

\begin{abstract}
Este artigo discute a associação entre accountability e auditoria interna, analisando particularmente até que ponto a última contribui para melhorias na primeira, nas Instituições de Ensino Superior (IES). Para analisar empiricamente a relação entre auditoria interna e accountability, o estudo baseia-se nos resultados de um questionário enviado aos órgãos de gestão de uma amostra de IES, com o foco principal na auditoria interna desenvolvida pelos gabinetes ou departamentos nessas instituições. $\mathrm{O}$ artigo contribui para entender como os órgãos de gestão percebem a auditoria interna para promover a transparência e a accountability nas IES, permitindo corroborar que a auditoria e, principalmente, a auditoria interna, serve a accountability. Com efeito, ela promove os princípios subjacentes às práticas de accountability. A informação proporcionada no âmbito das auditorias internas é reconhecida como contribuindo para melhorar a eficácia da gestão e ajudar na tomada de decisões. As IES que desejem criar um gabinete de auditoria interna ou aprimorar o papel de um gabinete já existente, devem desenvolver as atividades desse serviço de modo a que se torne um instrumento para apoiar a accountability e a boa governança da organização. A amostra foi constituída por IES públicas portuguesas, universidades e institutos politécnicos. Apesar de existir uma certa convergência internacional em relação a este tipo de organizações do setor público, bem como em relação aos seus propósitos e governança, certas especificidades contextuais podem limitar a generalização dos resultados desta pesquisa, para outras jurisdições.
\end{abstract}

Palavras-chave: avaliação de desempenho; transparência; responsabilidade; universidades públicas; Portugal.

\section{El papel de la auditoría interna en la promoción de la accountability en las Instituciones de Educación Superior}

Este artículo discute la asociación entre la accountability y la auditoría interna, en particular analizando hasta qué punto esta última contribuye a mejorar la primera, en las Instituciones de Educación Superior (IES).

Para analizar empíricamente la relación entre la auditoría interna y la accountability, el estudio se basa en los resultados de una encuesta enviada a los consejos de administración de una muestra de IES, con el enfoque principal en la auditoría interna realizada por las oficinas o departamentos en esas instituciones. El artículo contribuye a comprender cómo los consejos de administración perciben la auditoría interna para fomentar la transparencia y accountability en las IES, lo que permite corroborar que la auditoría, y particularmente la auditoría interna, sirve a la accountability. De hecho, ella promueve los principios subyacentes a las prácticas de accountability. Se reconoce que la información proporcionada en el ámbito de las auditorías internas contribuye a mejorar la efectividad de la gestión y ayuda en la toma de decisiones. Las IES que desean crear una oficina de auditoría interna o mejorar el papel de una existente, deben desarrollar las actividades de esta oficina para que se convierta en un instrumento de apoyo a la accountability y al buen gobierno de la organización. La muestra consistió en IES públicas portuguesas, universidades y politécnicos. A pesar de una cierta convergencia internacional con respecto a este tipo de organizaciones, así como con respecto a sus propósitos y gobernanza, ciertas especificidades contextuales pueden limitar la generalización de los resultados a otras jurisdicciones.

Palabras clave: evaluación de desempeño; transparencia; responsabilidad; universidades públicas; Portugal.

DOI: http://dx.doi.org/10.1590/0034-761220190267

Artigo recebido em 29 jul. 2019 e aceito em 03 fev. 2020.

ISSN: $1982-3134$ (c) (1)

[Versão traduzida]

A pesquisadora Susana Jorge faz saber que suas contribuições para o presente trabalho foram conduzidas no Centro de Pesquisa em Ciência Política (CICP), Universidade do Minho, com apoio da Fundação Portuguesa para a Ciência e a Tecnologia e do Ministério da Educação e Ciência de Portugal, por meio de financiamento nacional (UID/CPO/0758/2019). 


\section{The role of internal auditing in promoting accountability in Higher Education Institutions}

This paper discusses the link between accountability and internal auditing, particularly analyzing the extent to which the latter contributes to improve the former, in Higher Education Institutions (HEIs). This study applied a questionnaire to the management boards of a sample of HEIs, to empirical analyze the relationship between internal auditing and accountability. The main focus was on internal auditing carried out by the offices or departments in those institutions. The paper contributes to understand how management boards perceive internal auditing to foster transparency and accountability in HEIs, allowing to corroborate that auditing, and particularly internal auditing, favors the institutions' accountability. In effect, it promotes the principles underlying accountability practices. The information provided in the scope of internal audits is acknowledged as contributing to improve management effectiveness and helping in decision-making. HEIs wanting to create an internal auditing office or to enhance the role of an existing one, should develop this office's activities so that it becomes an instrument to support accountability and good governance of the organization. The sample consisted of Portuguese public HEIs, universities and polytechnics. Despite a certain international convergence regarding this type of public sector organizations, and regarding their purposes and governance, certain contextual specificities might limit the generalization of the findings for other jurisdictions.

Keywords: performance assessment; transparency; responsibility; public universities; Portugal.

\section{INTRODUÇÃO}

No âmbito do setor público, a mudança que ocorreu nas últimas décadas, conhecida como a Nova Gestão Pública (NGP), materializou-se na implementação de uma gestão descentralizada e orientada por objetivos. Baseada em critérios de economia, eficácia e eficiência (doravante designados como 3E’s), a Nova Gestão tem como principal objetivo maximizar o desempenho dos gestores públicos em benefício dos cidadãos, minimizando os níveis de consumo dos (escassos) dos recursos disponíveis (Pereira, Alledi, Quelhas, Bonina, Vieira, \& Marques, 2017).

A avaliação do desempenho no setor público acompanhou também as tendências do setor empresarial (Hood, 1991; Pereira et al., 2017), com a introdução na gestão dos serviços públicos de princípios elementares associados à avaliação dos serviços prestados e à aplicação de práticas de accountability, que visam uma melhoria do binómio qualidade/preço, tendo em conta as expetativas do cidadão/cliente (Sarrico, 2010). As ideias de transparência, participação e accountability ganharam visibilidade na gestão de diferentes entidades da Administração Pública - gestores e colaboradores são corresponsáveis pelos resultados alcançados em relação aos objetivos propostos em determinado período, com a introdução de indicadores de desempenho que devem ser constantemente monitorados (Liu, Cheng, Mingers, Qi, \& Meng, 2010; Wall \& Martin, 2003). Atualmente, há uma descentralização e delegação de poderes e competências baseadas num paradigma denominado como 'accountability no setor público'. Esse conceito representa uma ideia implícita e simplificada de transparência e prestação de contas, em que os gestores públicos assumem perante os cidadãos a responsabilidade de criar mecanismos que permitam aumentar o grau de confiança entre os mesmos (Martins, 2012).

Na sequência das várias mudanças na Administração Pública, para fazer face aos novos desafios sociais e económicos, o ensino superior foi, também, alvo de alterações. De facto, as instituições confrontam-se com um elevado número de novos problemas que exigem soluções inovadoras e mudanças substanciais nos modelos tradicionais de gestão académica (Martins, 2012; Santiago \& Carvalho, 2008).

As mudanças verificadas traduziram-se na descentralização do processo da tomada de decisão por parte do poder político, conferindo a estas entidades maior autonomia e responsabilidade, passando os órgãos de gestão a ser equiparados por alguns autores aos órgãos executivos das empresas privadas (Afonso, 2009; Christopher, 2012; Marques, 2012). Em decorrência dessas mudanças, na medida em 
que controla apenas as variáveis mais relevantes e atribui uma maior responsabilização aos órgãos de gestão das IES pela sua condução e ação (Silva, 2016), enquanto implementa um conjunto de mecanismos que os responsabilizam pelo gerenciamento dos bens públicos.

Neste contexto em que a gestão das IES se aproxima cada vez mais das empresas privadas (não negligenciando os aspetos de natureza social e cultural para os quais as mesmas se encontram direcionadas), com o presente artigo pretende-se analisar a relação existente entre a auditoria desenvolvida interna e externamente e a promoção da accountability nas IES portuguesas. Mais especificamente, o estudo analisa empiricamente a percepção dos grupos gestores sobre o papel da auditoria nas IES, particularmente as auditorias internas, na promoção da accountability, utilizando como grupos de estudo as IES públicas portuguesas (universidades e institutos politécnicos).

O estudo da temática em apreço revela-se oportuno e relevante, dadas as alterações sentidas ao nível do sistema contabilístico e de reporte, e a importância que os princípios da accountability têm assumido na boa governança das entidades públicas, nomeadamente nas IES. Tais reformas têm permitido disponibilizar informação na prestação de contas que conduzem à responsabilização pelos resultados alcançados na gestão do erário público, assegurando ainda que são satisfeitas as necessidades ou interesses dos diferentes stakeholders. Ao ser reconhecida a importância da auditoria para dar suporte ao atingimento dos objetivos organizacionais e para assegurar a credibilidade da informação divulgada, evidencia-se uma relação entre a accountability e a auditoria que importa analisar (International Federation of Accountants \& The Chartered Institute of Public Finance \& Accountancy [IFAC \& CIPFA], 2014).

Estudos empíricos sobre o relacionamento entre auditoria e accountability são quase inexistentes, especialmente nas IES. De fato, não foram encontrados estudos empíricos que relacionem estes dois temas no setor educacional. Alguns estudos versaram meramente sobre o papel da auditoria, controlo interno ou accountability nas organizações do setor público.

Teixeira (2006) menciona que este tipo de auditoria tem vindo a consolidar o seu papel na estrutura da governação das organizações, sendo reconhecidos os efeitos positivos da mesma pelos órgãos de gestão no que respeita à gestão de risco, no auxílio na prevenção de perdas e na identificação de oportunidades de melhoria dos instrumentos de gestão e controlo das operações. A auditoria também permite informações mais confiáveis, contribuindo, dessa forma, para maior eficácia na gestão e na tomada de decisão. Saraiva (2010) analisou a importância da auditoria interna nas instituições politécnicas de Portugal, concluindo que os órgãos de gestão consideram que é mais importante prevenir erros e omissões do que contribuir para a avaliação da eficiência nos procedimentos de assistência na tomada de decisão desses órgãos de gestão. Rodrigues (2017) analisou as atividades desenvolvidas pela auditoria interna nas universidades federais brasileiras, evidenciando que o objetivo é controlar a gestão, especialmente com ênfase na própria gestão e na auditoria operacional. Muitas atividades estão relacionadas ao direcionamento e à assistência na tomada de decisões dos gestores, ao monitoramento da implementação das recomendações dos órgãos de controle interno e externo e ao preparo da prestação de contas, promovendo, consequentemente, a transparência. Unidades de auditoria interna asseguram que os órgãos de gestão agem de acordo com a legislação e com os resultados relacionados aos 3E's da gestão de orçamento, de finanças, de patrimônio e de pessoal. Rodrigues, Machado, e Sampaio (2018) desenvolveram um estudo sobre o perfil profissional dos auditores internos das universidades federais brasileiras. Há uma predominância de pós-graduados em contabilidade, direito e administração e uma média de seis pessoas nas unidades de auditoria por instituição. Em aproximadamente metade das IES, não havia pessoal suficiente. Evidenciaram certo 
risco de falta de recursos e eficácia no processo, devido ao fato de ficar a cargo de cada IES decidir sobre a estrutura de sua unidade de auditoria interna.

Este estudo tem como objetivo preencher a lacuna existente, evidenciando a relação aparente entre as práticas de auditoria (interna e externa) e a accountability, mesmo que focada na perspectiva dos órgãos gestores. A relevância do contexto das IES públicas é notável, devido aos recursos disponibilizados, à meta social e à missão de desenvolver cultura e conhecimento, que fazem as práticas da contabilidade pública mais importantes.

Em seguida, será feita a revisão de literatura, que conceituará accountability e auditoria, discutirá a relação entre os dois conceitos, com ênfase nas IES. As seções posteriores tratarão das questões metodológicas do estudo empírico, da apresentação e da discussão dos resultados e, finalmente, da conclusão.

\section{ENQUADRAMENTO TEÓRICO}

\subsection{Accountability}

Pese embora o conceito de accountability tenha uma longa tradição histórica na ciência política e na contabilidade, o mesmo é atualmente considerado como multifacetado, complexo, e de difícil delimitação (Carvalho, 2009; Lindberg, 2013). O termo também é de difícil tradução para a língua de Camões (Pinho \& Sacramento, 2009). É, no entanto, consensual a sua associação aos princípios da responsabilização e da obrigação de prestar contas, cujo principal objetivo é a transparência na gestão, tendo em conta indicadores de desempenho.

Neste enquadramento inicial sobre o conceito em apreço, destaca-se a definição apresentada por Yuji Ijiri, em 1975, em que o autor releva uma vertente mais contabilística, mencionando que a accountability é a razão de ser da contabilidade, uma vez que os registos (bookkeeping) são efetuados por um agente responsável (accountable) pelo dever de prestar contas perante determinada entidade, de forma a cumprir as obrigações legais a que a mesma se encontra vinculada (Nakagawa, Relvas, \& Dias, 2007).

Por sua vez, Campos (1990) explica que a accountability deriva da obra de Frederich Mosher publicada em 1968, onde é apresentada como sinónimo de responsabilidade objetiva. Ou seja, corresponde à obrigação de uma pessoa ou uma entidade responder perante outra, pelo desempenho e resultados das suas ações, estando a mesma sujeita a prémios e incentivos pelo seu cumprimento ou a penalizações e represálias (Pinho \& Sacramento, 2009).

Ao longo dos tempos, o conceito de accountability tem ganhado uma nova dimensão, em que a prestação de contas não assume apenas uma obrigação imposta pela legislação em vigor, mas sim uma responsabilização individual perante os diferentes stakeholders pelo desempenho das funções delegadas, tendo em conta os interesses de quem elege ou nomeia, assim como os objetivos definidos num plano de ação.

Com o intuito de sintetizar as diferentes definições e conceitos existentes, Rocha (2008, p. 3) refere-se à accountability como a "responsabilização permanente dos gestores públicos em razão dos atos praticados em decorrência do uso do poder que lhes é outorgado pela sociedade". Assim, a accountability é, por si só, um elemento imprescindível à boa governança, responsabilizando quem toma decisões e evitando o abuso de poder (Cameron, 2004), sendo apresentada como um contributo utilizado "não só para controlar a gestão dos recursos públicos, mas também como forma de estimular ganhos económicos e de eficiência desses mesmos recursos” (Carvalho, 2009, p. 30). Essa ideia já 
tinha sido anteriormente defendida por Mulgan (2000), segundo o qual a accountability poderá ser entendida como um mecanismo de controlo dos resultados e do diálogo com o cidadão, aumentando a capacidade de dar resposta às suas necessidades.

Em um sentido amplo, a accountability é realizada por cidadãos que exercem seu poder de voto para recompensar ou punir, seja por eleição ou exclusão, seus legisladores e representantes. Isso acontece também no desempenho das atividades diárias e na maneira como os agentes públicos e as organizações se comportam (Rocha, 2009).

Embora a diversidade presente nas várias definições de accountability seja significativa, constatase a existência de três elementos comuns, como sejam: responsabilização objetiva pelo desempenho individual; prestação de contas; e transparência dos atos praticados, tendo em conta a avaliação do desempenho baseado em indicadores qualitativos e quantitativos.

Face ao descrito, os principais traços distintivos da accountability podem resumir-se nos seguintes princípios:

- Responsabilização: Lindberg (2013) identifica como denominador comum a responsabilização associada a quem tem o poder de decisão que, por sua vez, tem a obrigação de prestar contas através de informação mensurável e de indicadores verificáveis. Os gestores públicos são responsabilizados pelos atos praticados, através da atribuição de recompensas materiais (de mérito) ou sanções (coações), considerando os resultados obtidos e o cumprimento dos normativos legais ou regulamentares existentes.

- Prestação de contas: A accountability e a prestação de contas representam um binómio que se relacionam entre si, porque a prestação de contas constitui um meio privilegiado na promoção da accountability, na medida em que a informação disponibilizada pelos órgãos de gestão permite a sua responsabilização sobre os atos praticados na gestão do erário público (Carvalho, 2009). Por conseguinte, para que haja accountability, é necessário ter acesso à informação sobre as ações desenvolvidas e os recursos utilizados, assim como ao desvio e respetiva justificação entre o planejado e o executado, pois toda a atribuição de responsabilidade deriva da disponibilização desta informação, pertinente e oportuna. A sua preparação representa o cumprimento de um requisito legal, levando em conta os aspetos previstos nos normativos legais em vigor e conter indicadores mensuráveis quanto ao grau de satisfação dos cidadãos pelos serviços prestados, sendo a qualidade referida como um fator chave de sucesso a longo prazo (Cameron, 2004; Carvalho, 2009; Lindberg, 2013).

- Transparência: Ao considerar um conceito mais abrangente de accountability, deve ser exigida não apenas a disponibilização de informação, como também que esta seja confiável e acessível, contribuindo para a promoção da transparência. A informação disponibilizada aos stakeholders deve obedecer a critérios de compreensibilidade, relevância, confiabilidade e tempestividade (Gonçalves, 2011). A ISSAI 20 - Principles of transparency and accountability aponta a accountability e a transparência como dois elementos essenciais à boa governança, sendo a transparência um elemento fundamental para a promoção do combate à corrupção, da melhoria na gestão e da responsabilização (International Organization of Supreme Audit Institutions [INTOSAI], 2010).

\subsection{Auditoria}

Em termos conceptuais, auditoria deriva etimologicamente do latim audire, que significa 'ouvir' (Crepaldi, 2016). Em termos históricos, embora tenham sido identificadas evidências de uma atividade 
similar à auditoria durante o império romano, é com a revolução industrial na Grã-Bretanha, no século XIX, que surge a auditoria como é hoje compreendida, fruto do crescimento do número de empresas industriais e comerciais, e da consequente necessidade de implementar procedimentos contabilísticos e medidas de controlo interno eficientes (Costa, 2010).

Considerando as mudanças ocorridas nas últimas décadas na estrutura das organizações, bem como na definição dos seus objetivos, cada vez mais vastos e abrangentes, a auditoria deixou de ter “[...] um papel primário na detecção de fraude, concretamente até o início do século XX”, passando a ser responsável "pela emissão de opinião sobre a informação e/ou relato financeiro gerado pelas empresas, para certificar se o mesmo é credível e fidedigno em relação à realidade que pretende espelhar" (Moreira, 2014, p. 89).

Contudo, numa economia cada vez mais globalizada e competitiva, em que os princípios de accountability apresentam uma relevância nas organizações empresariais e no setor público, a responsabilidade pela deteção e prevenção da fraude compete não só às pessoas a quem incumbe a governança das entidades, como também à gestão das mesmas (Costa, 2010). Constata-se assim que a auditoria tem se adaptado ao ambiente onde as organizações exercem a sua atividade, dando resposta às novas exigências sociais e económicas, e tornando-se, crescentemente, um instrumento propulsor de mudança e inovação organizacional, que na verificação de cada matéria tem em conta os normativos existentes e os princípios dos 3E's (Pinheiro, 2010; Teixeira, 2006), aumentando para uma abrangência de gestão geral e não somente essencialmente financeira.

Kagermann, Kinney, Kutting, e Weber (2008, p. 2) definem auditoria como um "processo sistemático de obtenção objetiva e avaliação de evidências sobre o estado atual de uma entidade, área, processo, comparando-as com critérios previamente aceites, sendo os resultados comunicados aos usuários previstos". Para Crepaldi (2016, p. 3), auditar pode ser definido como uma "pesquisa, estudo sistemático e avaliação dos registos financeiros, operacionais e de procedimentos de transações de uma entidade".

Sendo as ações de auditoria de caráter obrigatório apenas para algumas entidades organizacionais (e.g. instituições financeiras, empresas de capital aberto e órgãos governamentais), o âmbito do trabalho efetuado depende da decisão de cada organização (Rodrigues, 2017). Contudo, é atribuída uma importância crescente à realização de auditorias, tendo em conta a classificação quanto ao sujeito que as realiza, uma vez que as ações desenvolvidas interna e externamente aumentam a eficácia da organização e a confiabilidade da informação (Teixeira, 2012). Por isso, é feita a distinção entre a auditoria interna e externa. No entanto, é mais difícil definir o papel de um auditor interno do que de um auditor externo, sendo o desenvolvimento do trabalho desses auditores complementar (Morais \& Martins, 2013).

O conceito de auditoria externa encontra-se maioritariamente associado à validação da informação contida nos relatórios financeiros padronizados, para que a informação disponibilizada aos diferentes stakeholders, externos e internos, seja credível e fiel, demonstrando assim a capacidade de criação de valor e risco associada ao desenvolvimento da atividade da entidade no futuro. Essa categoria de auditoria "é efetuada por profissionais externos não subordinados à entidade", tratando-se normalmente de auditorias ocasionais (Morais \& Martins, 2013, p. 22).

Por sua vez, no que respeita à auditoria interna, o Instituto de Auditores Internos a define como uma atividade independente, de garantia e consultoria, destinada a acrescentar valor e melhorar as operações da organização. É uma atividade de avaliação fornecida pela entidade e para si mesma (International Federation of Accountants [IFAC], 2014) e presta assistência à organização para atingir seus objetivos por meio de uma abordagem disciplinada para assegurar e melhorar a eficácia na gestão de riscos, no 
controle interno e nos processos de governança (IIA, 2012; IFAC, 2014; Leung, Cooper, \& Pereira, 2011). "Auditoria interna é uma função de suporte de gestão, baseada em um processo sistemático, usando técnicas, metodologias e ferramentas próprias da auditoria” (Morais \& Martins, 2013, p. 91).

Auditores internos devem depender diretamente dos órgãos de gestão, ser considerados como elementos do staff e atuar de forma independente e objetiva (Costa, 2010).

\subsection{Auditoria e accountability nas IES}

O relatório intitulado The International Framework: Good Governance in the Public Sector (IFAC \& CIPFA, 2014) refere-se aos principais fatores subjacentes à boa governança do setor público, que se encontram ilustrados na Figura 1. Considerando os elementos envolvidos na relação entre os vários fatores, as ações descritas no item $\mathrm{G}$ relacionam-se com transparência, registro e auditoria, na medida em que constituem requisitos essenciais à promoção da accountability.

\section{FIGURA 1 RELAÇÃO ENTRE OS PRINCÍPIOS SUBJACENTES À BOA GOVERNANÇA DO SETOR PÚBLICO}

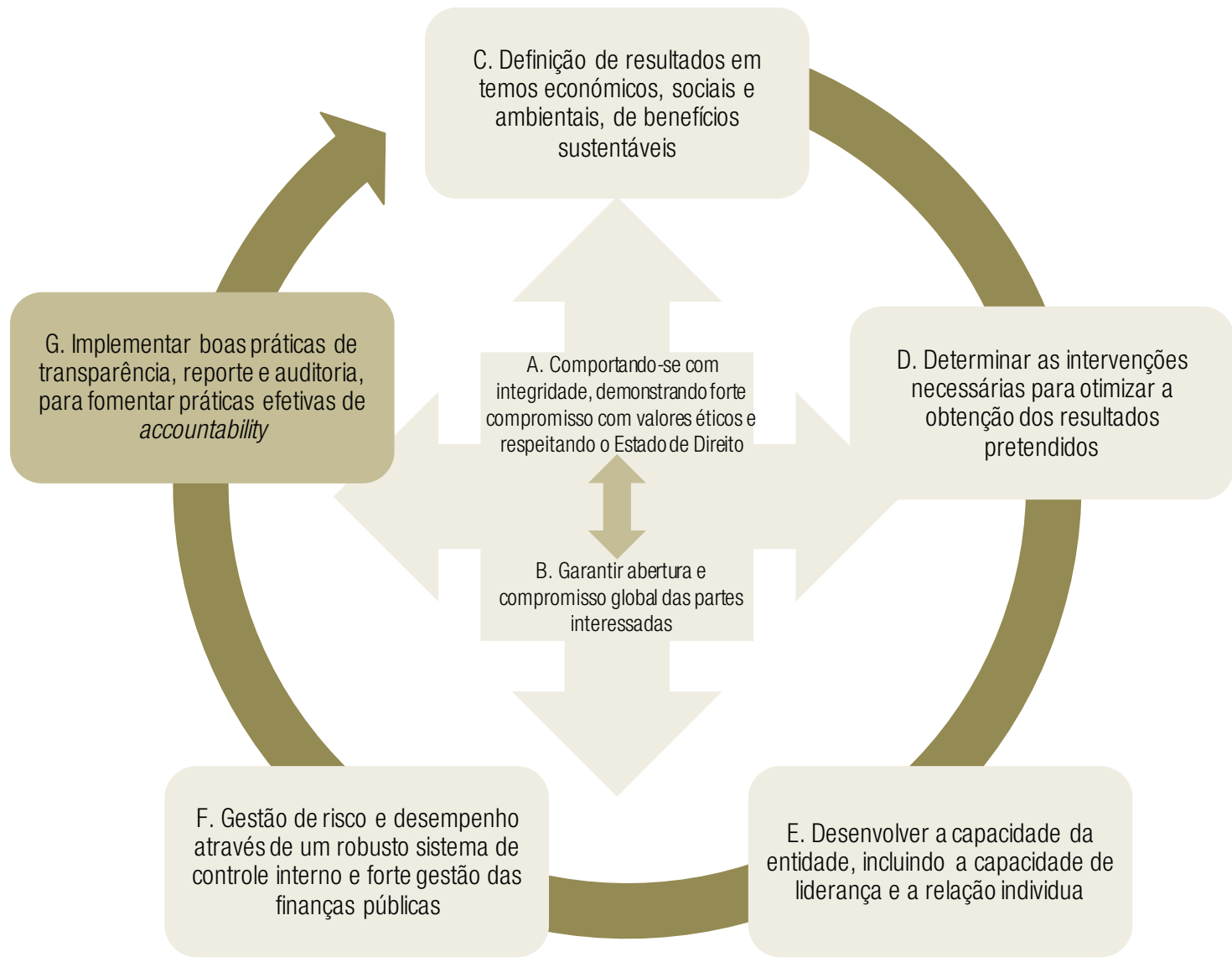

Fonte: Elaborada pelos autores com base em IFAC e CIPFA (2014). 
Nesse contexto, a boa governança requer ações de auditoria (externas e/ou internas) que reforçam a credibilidade da gestão pública, promovendo a prestação de contas fiável e responsável, e a transparência, bem como o aumento da capacidade dos stakeholders exercerem controlo sobre as ações dos órgãos de gestão, responsabilizando-os pelas mesmas. Neste sentido, o papel dos auditores no setor público deve promover uma ligação direta entre a transparência e a credibilidade dos órgãos de gestão, garantido que os objetivos estratégicos são alcançados, levando em conta os valores éticos estabelecidos e os normativos legais existentes (Domingos, 2015; IIA, 2012).

As ações de auditoria constituem, em princípio, um reforço dos principais pilares definidos para a accountability, uma vez que permitem a verificação e controlo da atuação dos órgãos de governo. Desse modo, a auditoria reforça: a confiança no sistema democrático; a prevenção da corrupção e do abuso de poder; a melhoria no funcionamento, eficácia, capacidade de resposta e aprendizagem; e por fim, a própria legitimidade dos órgãos de gestão (Bovens, 2005, 2006; Speijcken \& Bakker, 2011).

Por tradição, a auditoria no setor público - referida por vezes como auditoria pública, governamental, estatal ou da gestão público - e que doravante será designada como auditoria pública, baseia-se no conceito clássico de auditoria, ou seja, na legalidade das contas, fundamentado numa opinião sobre factos passados, limitada ao controlo financeiro e orçamentário implementado (Dias \& Sarrico, 2008; Domingos, 2015). No entanto, em consequência das reformas da NGP e com a criação da INTOSAI, constata-se uma evolução deste conceito, que se encontrava inicialmente direcionado para o controlo das contas públicas (auditoria de regularidade que integra a auditoria financeira), para a auditoria de desempenho (Costa, Pereira, \& Blanco, 2006, INTOSAI, 2007). Por isso, atualmente, a auditoria assume um papel preponderante, não somente na validação de informações financeiras pela avaliação da concordância com as regras e padrões, de acordo com os princípios dos 3E's, mas também no controle de informações não financeiras e no monitoramento do desempenho não financeiro das entidades do setor público (Dias \& Sarrico, 2008; Domingos, 2015; Marques \& Almeida, 2004).

Tendo em conta a obrigação de prestação de contas (dever de accountability) por parte do gestor público, a informação e a divulgação dos resultados da atividade desenvolvida revelam-se um meio fundamental para a transparência e responsabilização pelos atos praticados, permitindo assim a identificação, por parte das entidades com poderes de controlo ou fiscalização, de potenciais erros e irregularidades. Em países desenvolvidos, as entidades públicas são submetidas a sistemas de controle que têm como objetivo comprovar que elas satisfazem os princípios da accountability e limitar o poder dos grupos gestores. Esses sistemas incluem auditar ações que podem ser realizadas por agentes de dentro e de fora da entidade auditada.

Contudo, apesar da aparente relação entre auditoria e accountability, parece que ainda há um longo caminho para que a auditoria promova os conceitos da accountability nas organizações do setor público. É necessário que se utilizem métodos e técnicas focadas nos princípios dos 3E’s, permitindo aos gestores públicos serem responsáveis pelos resultados alcançados em suas organizações (Carvalho, 2009; Montenegro \& Celente, 2016).

Quanto ao contexto das IES, as mudanças observadas em seus modelos de gestão, baseados nos princípios da NGP, particularmente relacionados à accountability, fortaleceram a autonomia das instituições, fazendo com que a avaliação de desempenho fosse compulsória. Esse modelo objetiva reduzir a dependência financeira do orçamento do Estado (erário público), pressionando-os a procurar 
fontes alternativas de financiamento; aumentar suas receitas fornecendo novos serviços; introduzir sistemas de gestão por resultados, levando os órgãos de gestão a uma autonomia operacional; e considerar princípios económicos e financeiros baseados nos critérios dos 3E’s. Com isso, a governança dessas entidades passa a ter influência nos resultados que possam alcançar (Marçal-Grilo, 2003; Marques, 2014).

Em termos gerais, a autonomia de uma instituição refere-se à capacidade que lhe é conferida (através de uma delegação de competências) para realizar as próprias escolhas, tendo em conta os seus objetivos e missão. Na sequência das reformas implementadas nas IES, verifica-se um aumento do controlo exercido sobre as despesas públicas, maior responsabilização institucional e flexibilização na sua relação com o governo e com a sociedade em geral. O controlo do Estado é assim substituído pela autonomia com supervisão, com crescentes solicitações sociais relativas à relevância das IES, assim como à accountability das mesmas (Afonso, 2009; Christopher, 2012; Marques, 2012).

Em suma, podemos considerar que a tendência de aumento da autonomia das instituições de ensino superior nos últimos anos traduz-se também no incremento da accountability, colocando assim novos desafios quanto ao equilíbrio deste binómio, tendo em conta a definição de políticas de gestão que permitam atingir melhores resultados nas suas principais áreas de atuação, nomeadamente o ensino e a investigação (Guri-Rosenblit \& Sebkova, 2004). Em geral, accountability nas IES tomam variadas formas, como licenciamento e acreditação de programas, mecanismos de alocação de fundos e estruturas essenciais (Semyonov \& Platanova, 2017).

Neste âmbito, as ações de auditoria desenvolvidas, quer por órgãos internos, quer por entidades externas, afiguram-se como instrumentos relevantes de controlo interno e externo para a apuração, de uma forma transparente, de responsabilidades na avaliação do desempenho dos órgãos de gestão, permitindo assim a identificação de eventuais desvios face aos objetivos planejados, aos erros ou irregularidades.

\section{OBJETIVOS, METODOLOGIA E DADOS}

Este estudo tem como propósito proceder à análise empírica do papel da auditoria e a sua importância na promoção da accountability nas IES portuguesas, tomando como referência a perspetiva dos órgãos de gestão. O quadro 1 apresenta os objetivos $(\mathrm{Ob})$ e as perguntas de pequisa $(\mathrm{PP})$, iniciando com uma análise geral e partindo para a contribuição específica nas auditorias internas.

De acordo com as regras de controle no Manual de Auditoria e Procedimentos Tribunal de Contas Português (Tribunal de Contas, 1999), os auditores internos são os principais atores na auditoria interna das IES em Portugal.

Para avaliar as percepções das organizações, um questionário foi enviado para os órgãos de gestão de todas as IES públicas - 14 universidades e 20 institutos politécnicos. O questionário foi organizado em três seções de perguntas relacionadas a informações institucionais, o papel da auditoria na IES e o papel específico da auditoria interna para o órgão gestor. Foram usadas perguntas fechadas, a maioria com a utilização da escala Likert para resposta de 1 a 5 (sendo 1 a de menor valor e 5 a de maior valor), objetivando avaliar o grau de importância que os indivíduos atribuíam a cada questão (Sampieri, Fernández, \& Batista, 2006). Assim, a amostra ficou nas 26 respostas válidas, correspondendo a uma taxa de $76 \%$. A análise dos dados foi essencialmente descritiva, utilizando análise de frequência em último caso. 


\section{QUADRO 1 OBJETIVOS E PERGUNTAS DE PESQUISA}

Ob1: Como os órgãos de gestão entendem 0 papel da auditoria em geral nas IES.

Ob2: Como os órgãos órgãos de gestão entendem o paple da auditoria interna na promoção dos princípios de accountability nas IES.
PP1: Qual é a importância da auditoria em geral nas IES?

PP2: A auditoria interna constitui um instrumento de controle na avaliação do uso de recurso público, levando em consideração os princípios dos 3E's? (perspectiva de desempenho e de resultados)

PP3: A auditoria interna contribui para a promoção de transparência na divulgação das informações sobre as responsabilidades dos órgãos de gestão em cada IES? (perspectiva da confiança e da transparência)

PP4: A auditoria interna contribui para a promoção da tomada de responsabilidades nas IES? (perspectiva do risco e da responsabilidade)

PP5: Os mecanismos de controle foram implementados para monitorar as recomendações sugeridas pelos auditors internos?

PP6: As recomendações sugeridas nos relatórios de auditoria interna promovem a accountability dentro das IES?

Fonte: Elaborado pelos autores.

\subsection{Análise da amostra}

Dezoito das vinte e seis (69\%) entidades da amostra eram instituições politécnicas. A maioria das respostas veio das entidades localizadas nas regiões do centro e do norte de Portugal, onde as IES são mais concentradas. Quanto às dimensões (Figura 2), metade das IES tem menos de 5.000 estudantes; esses são essencialmente de instituições politécnicas (65\%). As Universidades são maiores: duas das oito têm mais de 20.000 estudantes. A média de estudantes das universidades é de 12.401, enquanto dos institutos politécnicos é de 5.521 .

\section{FIGURA 2 NÚMERO DE ESTUDANTES POR TIPO DE INSTITUIÇÃO}

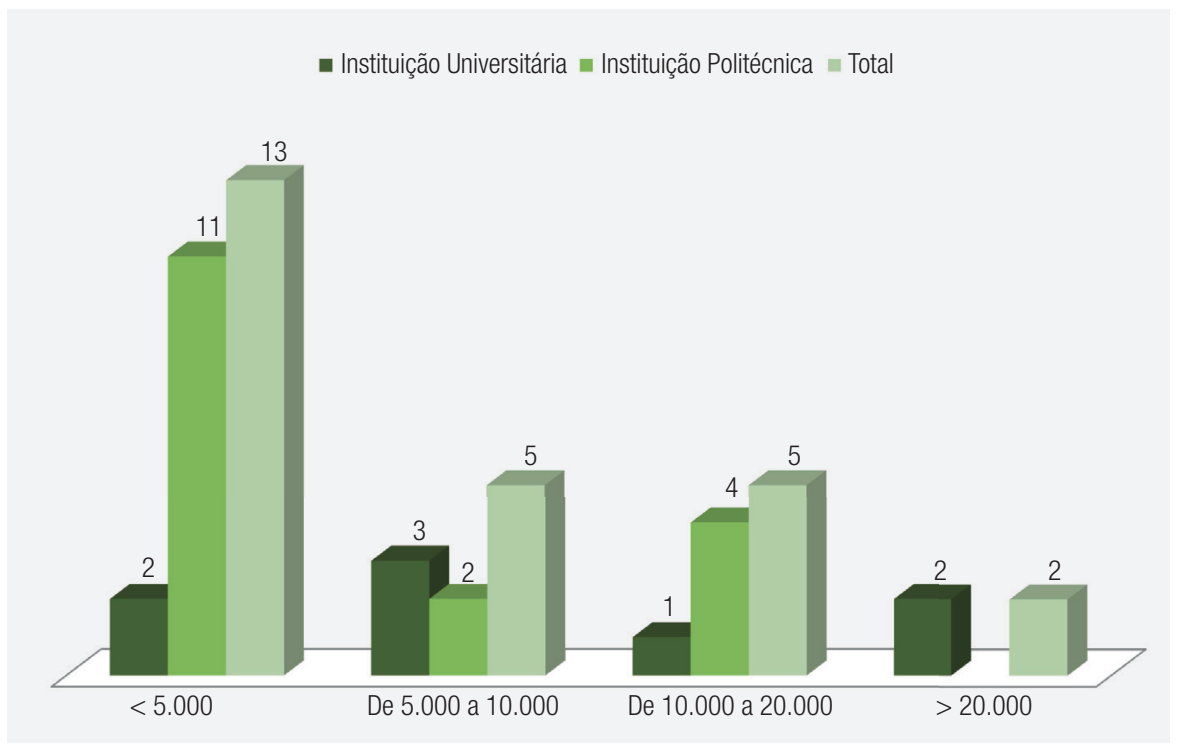

Fonte: Elaborada pelos autores. 


\section{RESULTADOS}

Nesta seção, os resultados serão apresentados seguindo a ordem dos objetivos e das perguntas de pesquisa registrados no Quadro 1.

\subsection{A auditoria nas IES}

Os indivíduos responderam a perguntas sobre diferentes tipos de auditoria realizadas em sua instituição, considerando os objetivos propostos, assim como meios utilizados de acordo com a distinção apresentada no Manual de Auditoria e Procedimentos do Tribunal de Contas (Tribunal de Contas, 1999).

Como mostra a Figura 3, auditoria financeira apresentou o maior número de respostas $(n=24)$, realizada externamente em aproximadamente $36 \%$ das instituições e internamente e externamente em $64 \%$ (somente uma IES não realiza este tipo). Por isso, pode-se dizer que assegurar a conformidade das obrigações financeiras é a maior preocupação das IES, especialmente devido às obrigações legalmente impostas em relação à prestação de contas.

Em seguida, com 22 respostas (85\% das IES), foi feita a pergunta sobre auditoria de projetos e programas e auditoria de qualidade, realizada em $45 \%$ dos casos internamente e externamente simultaneamente. O número mais baixo de respostas se relaciona com a auditoria de sistemas, realizada por 18 instituições, correspondendo a 69\% das entidades respondentes.

Quanto ao tipo de auditoria de acordo com o tamanho da IES, exceto para a auditoria financeira, de projetos e programas, o uso de meios internos prevalece sobre os externos na maioria dos tipos de auditoria, independentemente do tamanho da organização. Nas IES maiores ( $\mathrm{n}=2$ universidades) todos os tipos de auditoria, exceto as de qualidade, são realizados por meios internos e externos simultaneamente.

\section{FIGURA 3 TIPOS DE AUDITORIA POR DIMENSÃO DA INSTITUIÇÃO}
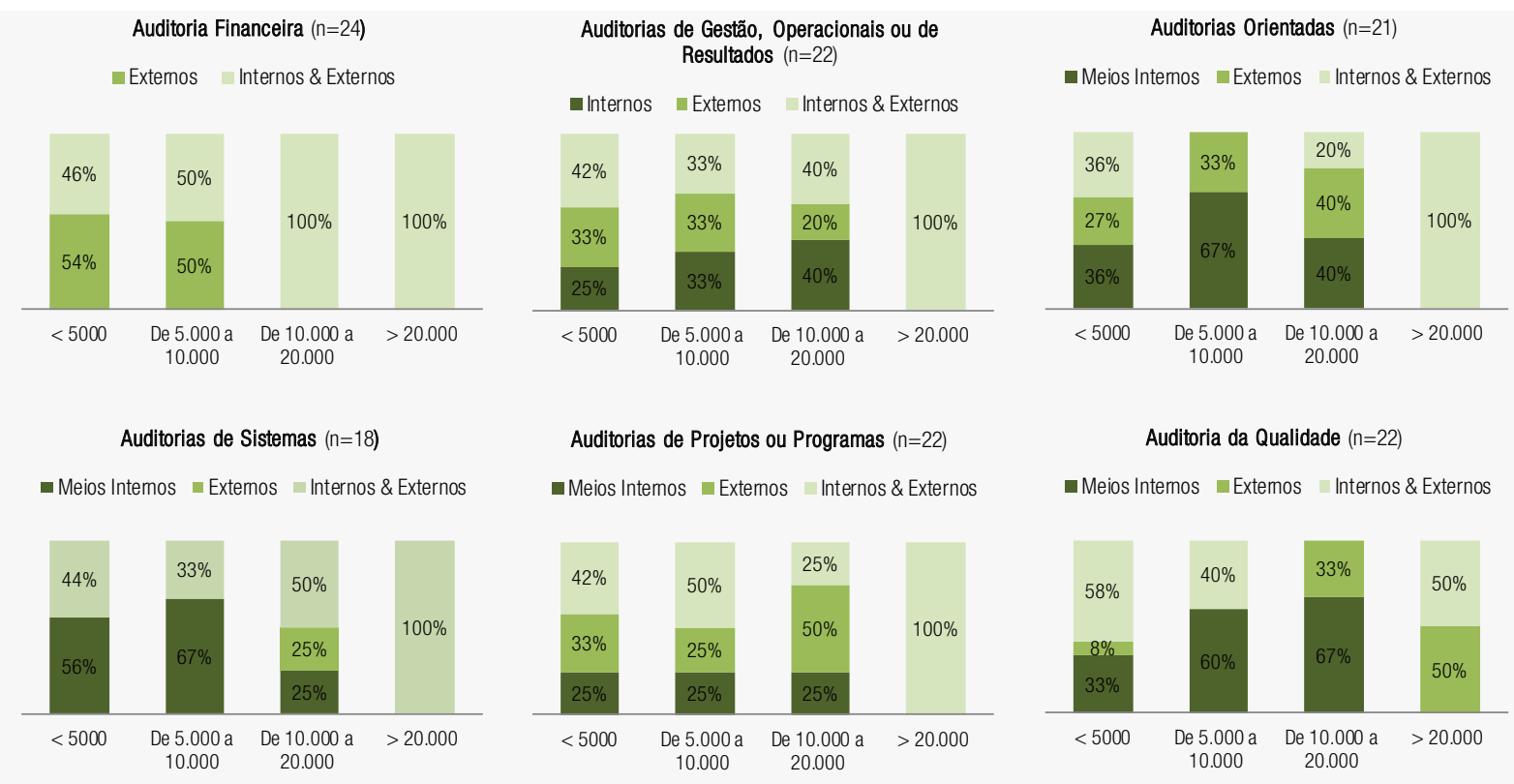

Fonte: Elaborada pelos autores. 
Quanto às entidades que foram auditadas pelo Tribunal de Contas (TC) nos últimos 5 anos, ela aconteceu em $54 \%$ das IES, das quais 36\% são universidades e $64 \%$ são institutos politécnicos. Considerando o tamanho, medido pelo número de estudantes matriculados em diferentes ciclos de estudo, constata-se que as duas universidades, que correspondem às instituições de maior dimensão da amostra, foram auditadas pelo TC no último quinquénio. Por outro lado, apenas $38 \%$ das IES com menos de 5.000 estudantes foram alvo de auditorias pelo referido organismo, no mesmo período de tempo. Na mesma linha das conclusões de Carvalho (2009) para autoridades locais, o número de IES auditadas pelo Tribunal de Contas nos últimos anos pode ser considerado baixo. Então, as IES não estão sujeitas a um completo controle externos pelo TC.

Finalmente, cerca de $58 \%$ das instituições $(n=15)$ têm um departamento de auditoria interna. Parece que há uma relação direta entre o tamanho da organização e a existência desse departamento, sendo mais comum nas IES com maior tamanho; todas as instituições com mais de 20.000 estudantes e $80 \%$ daquelas entre 10.000 e 20.000 estudantes têm um setor de auditoria interna.

As próximas seções apresentarão e discutirão as percepções coletadas na pesquisa dos órgãos gestores das IES sobre a importância da auditoria interna e seu papel na promoção da accountability - por meio dos pilares da avaliação de resultados, da transparência e responsabilidade, contribuindo com as práticas de boa governança na administração pública especialmente no subsetor de educação superior.

\subsection{A importância da auditoria interna}

A Tabela 1 apresenta a estatística descritiva de vários itens relacionados com a função da auditoria interna (Bovens 2006; Costa et al., 2006; IIA, 2012; Rodrigues, 2017; Speijcken \& Bakker, 2011).

Considerando a perspectiva dos grupos gestores, todos os itens mostram certo nível de importância de pelo menos 4; ou seja, todas as funções são consideradas relevantes na auditoria interna nas IES. Esses resultados também mostram que, em geral, o conceito de auditoria tem se desenvolvido, assim como maior importância tem sido dada a outras funções além das operações de conformidade e de legalidade realizadas. Em efeito, apesar de o item 1 ter grau de importância alto ou muito alto por todas as entidades respondentes $(n=26)$, evidenciando uma predominância da importância das auditorias de conformidade, o que apresenta ao público em geral uma imagem mais confiável da instituição (item 13), item que também é avaliado como de muita importância pela maioria das instituições $(n=14)$. Ao contrário, somente cinco itens (cerca de $36 \%)$ receberam índices muito baixos (item 9) ou baixos (itens 10,12, 13 e 14) de acordo com os papéis na auditoria interna por uma ou duas instituições politécnicas.

\section{TABELA 1 PAPEL DA AUDITORIA INTERNA NAS IES}

\begin{tabular}{|c|c|c|c|c|c|c|c|c|c|}
\hline & \multicolumn{3}{|c|}{ Estatística Descritiva } & \multicolumn{5}{|c|}{ Frequência } & \multirow[b]{2}{*}{$\begin{array}{c}\text { Sem } \\
\text { Resposta }\end{array}$} \\
\hline & Média & $\begin{array}{l}\text { Desvio } \\
\text { Padrão }\end{array}$ & N & $\begin{array}{l}\text { Muito } \\
\text { reduzido }\end{array}$ & Baixo & Neutro & Elevado & $\begin{array}{l}\text { Muito } \\
\text { Elevado }\end{array}$ & \\
\hline $\begin{array}{l}\text { [1] Assegurar o cumprimento dos normativos } \\
\text { legais e regulamentos internos existentes }\end{array}$ & 4,50 &, 510 & 26 & & & & 13 & 13 & \\
\hline [2] Assessorar e apoiar os órgãos de gestão & 4,42 &, 578 & 26 & & & 1 & 13 & 12 & \\
\hline
\end{tabular}


RAP | 0 papel da auditoria interna na promoção da accountability nas Instituições de Ensino Superior

\begin{tabular}{|c|c|c|c|c|c|c|c|c|c|}
\hline & \multicolumn{3}{|c|}{ Estatística Descritiva } & \multicolumn{5}{|c|}{ Frequência } & \multirow[b]{2}{*}{$\begin{array}{c}\text { Sem } \\
\text { Resposta }\end{array}$} \\
\hline & Média & $\begin{array}{l}\text { Desvio } \\
\text { Padrão }\end{array}$ & N & $\begin{array}{l}\text { Muito } \\
\text { reduzido }\end{array}$ & Baixo & Neutro & Elevado & $\begin{array}{l}\text { Muito } \\
\text { Elevado }\end{array}$ & \\
\hline $\begin{array}{l}\text { [3] Avaliar a otimização da gestão dos } \\
\text { recursos públicos }\end{array}$ & 4,32 &, 557 & 25 & & & 1 & 15 & 9 & 1 \\
\hline $\begin{array}{l}\text { [4] Avaliar a performance da entidade } \\
\text { tendo em conta os princípios da economia, } \\
\text { eficácia e eficiência }\end{array}$ & 4,23 & ,587 & 26 & & & 2 & 16 & 8 & \\
\hline $\begin{array}{l}\text { [5] Avaliar e monitorizar o sistema de } \\
\text { controlo interno implementado, quanto ao } \\
\text { seu grau de eficácia e eficiência }\end{array}$ & 4,46 &, 582 & 26 & & & 1 & 12 & 13 & \\
\hline [6] Avaliar o processo de gestão global & 4,24 &, 597 & 25 & & & 2 & 15 & 8 & 1 \\
\hline $\begin{array}{l}\text { [7] Coordenar e/ou apoiar as atividades de } \\
\text { comunicação e informação entre os órgãos } \\
\text { de gestão e os auditores externos }\end{array}$ & 4,00 & 800 & 26 & & & 8 & 10 & 8 & \\
\hline $\begin{array}{l}\text { [8] Identificar situações de risco e definir } \\
\text { estratégias eficazes para o seu controlo ou } \\
\text { mitigação das mesmas }\end{array}$ & 4,42 & ,643 & 26 & & & 2 & 11 & 13 & \\
\hline $\begin{array}{l}\text { [9] Prestar serviços de consultoria, } \\
\text { fornecendo informação útil e credível para } \\
\text { a tomada de decisão em tempo oportuno }\end{array}$ & 4,00 & 894 & 26 & 1 & & 4 & 14 & 7 & \\
\hline $\begin{array}{l}\text { [10] Promover a ética e assumir um papel } \\
\text { pedagógico }\end{array}$ & 4,23 & 815 & 26 & & 1 & 3 & 11 & 11 & \\
\hline $\begin{array}{l}\text { [11] Promover a gestão baseada nos } \\
\text { resultados inerentes ao desempenho }\end{array}$ & 4,12 & ,653 & 26 & & & 4 & 15 & 7 & \\
\hline $\begin{array}{l}\text { [12] Promover a transparência na } \\
\text { informação sobre a prestação de } \\
\text { responsabilidades }\end{array}$ & 4,35 & ,846 & 26 & & 2 & & 11 & 13 & \\
\hline $\begin{array}{l}\text { [13] Proporcionar uma imagem da } \\
\text { instituição mais credível perante o público } \\
\text { em geral }\end{array}$ & 4,46 & ,706 & 26 & & 1 & & 11 & 14 & \\
\hline $\begin{array}{l}\text { [14] Tornar visíveis as ações e } \\
\text { procedimentos internos }\end{array}$ & 4,27 & ,827 & 26 & & 1 & 3 & 10 & 12 & \\
\hline
\end{tabular}

Fonte: Elaborado pelos autores.

\subsection{Contribuições da auditoria interna para os princípios da accountability}

O primeiro aspecto a ser analisado nesta seção diz respeito ao papel da auditoria interna como um instrumento de controle na prestação de contas da gestão dos recursos públicos, levando em consideração os resultados alcançados e os respectivos desvios (desempenho), à luz dos princípios dos 3E's. Com o intuito de compreender a percepção dos órgãos de gestão sobre o assunto, seis objetivos da auditoria interna que contribuem para a premissa em análise (Domingos, 2015; IFAC 
\& CIPFA, 2014; Marques \& Almeida, 2004; Pinheiro 2010; Morais \& Martins, 2013; Saraiva, 2010) foram indicados, conforme Figura 4.

FIGURA 4 CONTRIBUTO DOS OBJETIVOS DA AUDITORIA INTERNA PARA 0 REFORÇO DO CONTROLO NA AVALIAÇÃO DA APLICAÇÃO DOS RECURSOS PÚBLICOS

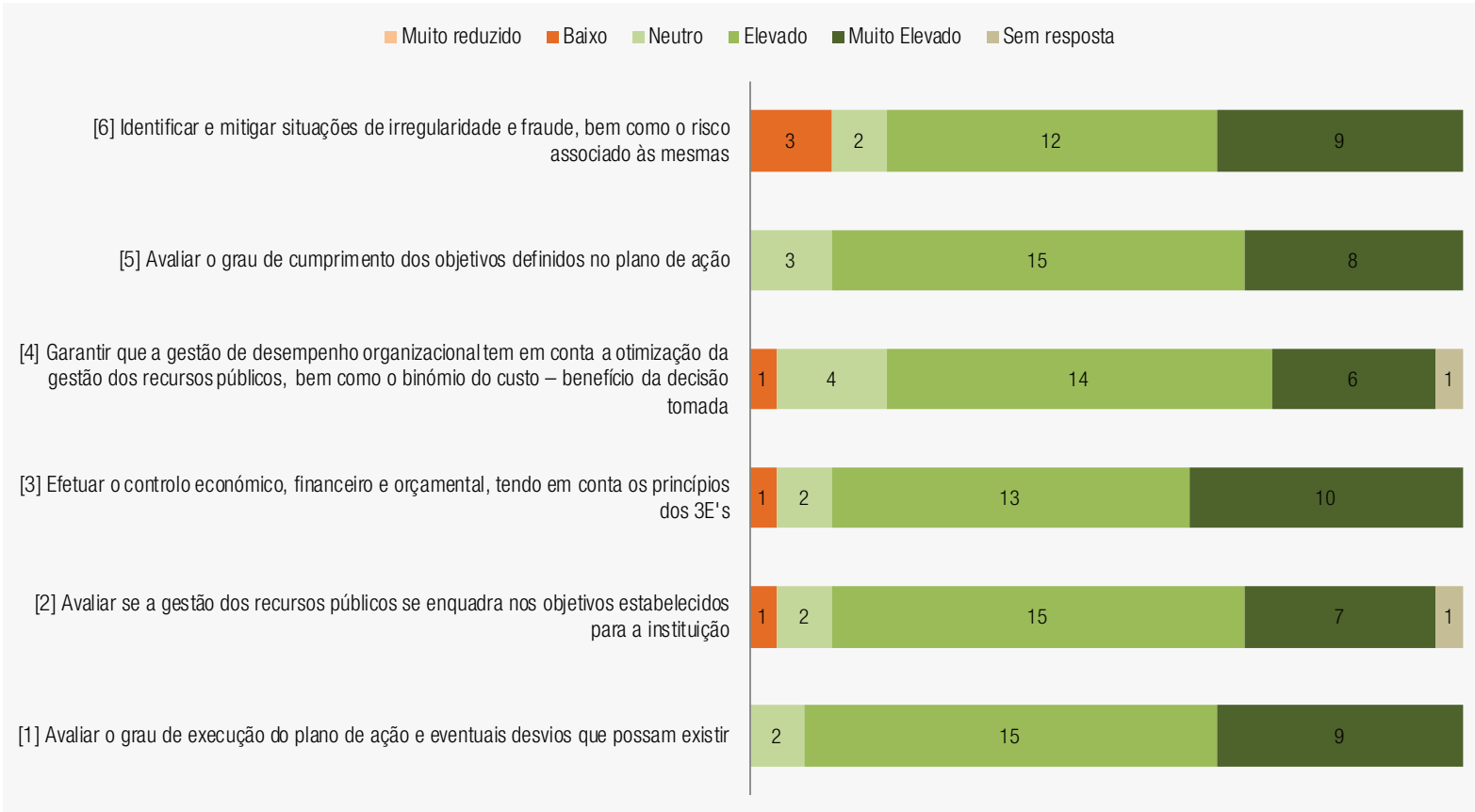

Fonte: Elaborada pelos autores.

A maioria dos respondentes atribuíram importância alta ou muito alta para todos os itens, sendo 4 o nível de importância mais frequente. O nível de concordância com todos os objetivos é maior do que 4,00, variando entre 4,00 e 4,27, respectivamente nos objetivos 4 e 1 . Por isso, a avaliação do grau de realização dos planos de ação e o levantamento dos possíveis desvios (objetivo 1) tem importância alta ou muito alta por $92 \%$ das entidades respondentes ( $n=24)$, seguida pelos objetivos 3 e 5 (com $88 \%$ das IES). Por sua vez, a identificação e a mitigação de situações irregulares ou fraudulentas (objetivo 6), é o objetivo que mais frequentemente mostra desacordo, sendo atribuído a ela baixo grau de concordância (nível 2) por $12 \%$ das IES $(\mathrm{n}=3)$.

A percepção sobre como a auditoria interna contribui para a promoção da transparência da informação para a accountability, foi avaliada com base nos sete objetivos da auditoria interna, como mostra a Figura 5. Esses objetivos incluem ações para monitorar e revisão informações fornecidas, contribuindo para a melhora da imagem da instituição frente aos diferentes stakeholders (Carvalho, 2009; IFAC \& CIPFA, 2014; IIA, 2012; INTOSAI, 2013) e para a credibilidade e a relevância da informação contida nos relatórios, contribuindo para o aumento da eficácia e da confiança da comunicação entre as IES e os stakeholders (IIA, 2012; INTOSAI, 2013; Montenegro \& Celente, 2016; Morais \& Martins 2013). 


\section{FIGURA 5}

\section{CONTRIBUTO DOS OBJETIVOS DA AUDITORIA INTERNA PARA PROMOÇÃO DA TRANSPARÊNCIA}

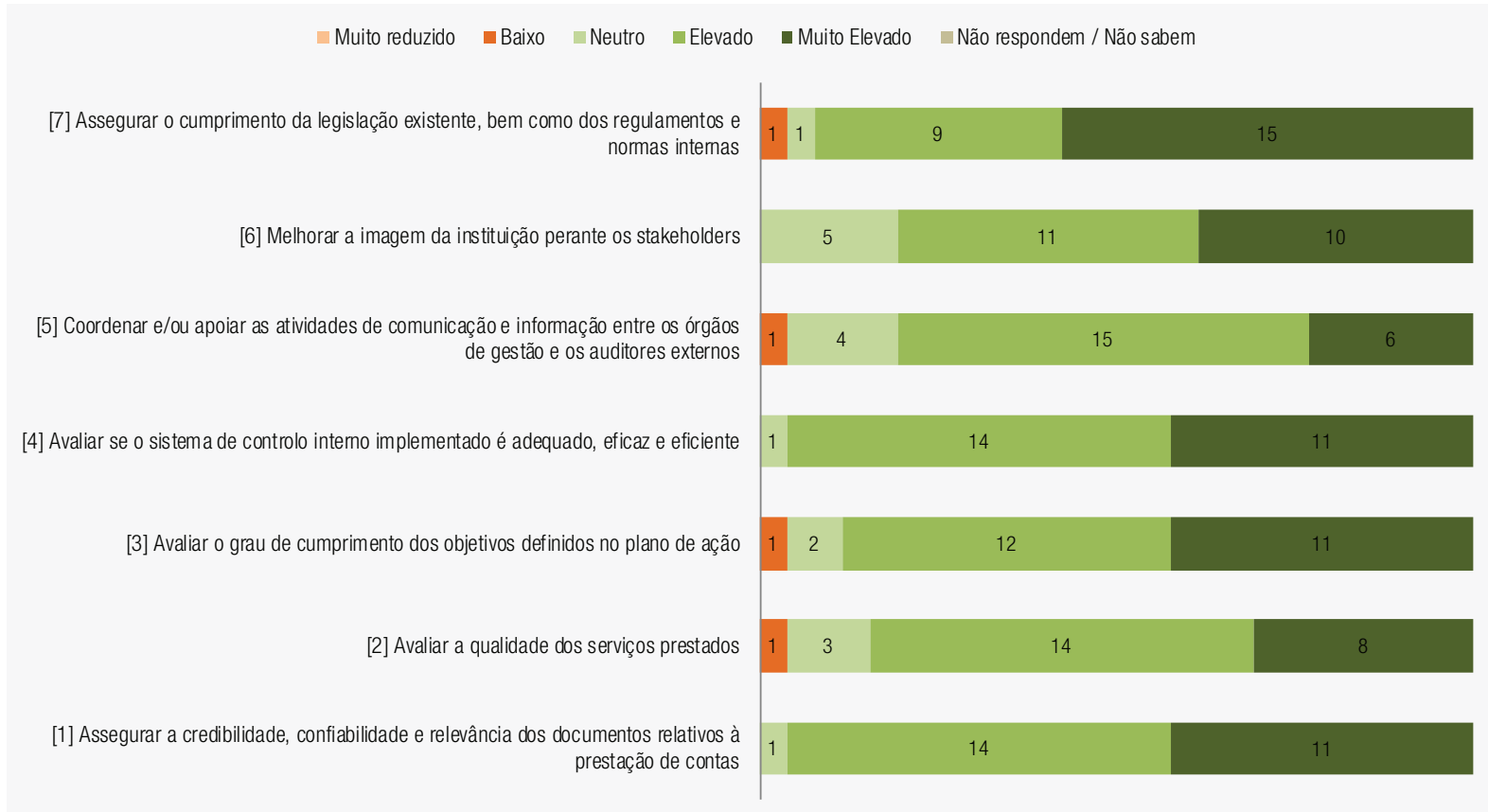

Fonte: Elaborada pelos autores.

Com base nas respostas obtidas, constata-se que a todos os objetivos foi atribuída uma importância elevada ou muito elevada por mais de $81 \%$ das IES, sendo, contudo, o valor de 4 o que aparece com maior frequência em todos os objetivos propostos, com exceção do sétimo (que é considerado por $58 \%$ dos inquiridos com uma importância muito elevada). À semelhança do princípio da avaliação de desempenho, o valor médio é superior a 4, variando entre 4 e 4,46, correspondendo o primeiro valor ao objetivo 5 e o segundo ao objetivo 7. Assegurar a credibilidade, confiabilidade e relevância dos documentos relativos à prestação de contas (objetivo 1) e avaliar se o sistema de controlo interno implementado é adequado, eficaz e eficiente (objetivo 4) obtêm a mesma frequência de respostas, existindo apenas uma instituição que assume uma posição neutra, sendo considerado para as restantes $(n=25)$ em um grau de concordância elevado e muito elevado. No sentido inverso, existe apenas uma instituição que classifica como baixo (nível 2 da escala) o contributo dado pelos objetivos 2, 3, 5 e 7.

Deve ainda realçar-se que a posição neutra assume uma maior importância face ao princípio anterior, uma vez que em todos os objetivos apresentados existe pelo menos uma instituição que assume esta posição, atingindo o seu valor máximo no objetivo 6 (com n=5, 19\% das IES). Relativamente a este facto, poderá assumir-se que, tendo em conta que a informação emanada nos relatórios de auditoria interna tem como principais destinatários os stakeholders internos à instituição, nomeadamente órgãos de gestão e serviços auditados, o campo de atuação na promoção da transparência encontra-se limitado.

Quanto à percepção sobre como a auditoria interna contribui para a promoção da responsabilidade, oito objetivos da auditoria interna foram apresentados aos órgãos gestores das IES, como mostra a Figura 6. Esses objetivos constituem a ética e os valores, o desempenho e os desvios que podem 
ocorrer, levando em conta as competências delegadas ou os objetivos propostos (Gomes, Fernandes, \& Carvalho, 2015; Gonçalves, 2011; IFAC \& CIPFA, 2014; INTOSAI, 2013), as contribuições para o controle e a mitigação dos riscos inerentes à tomada de decisão, prevenindo qualquer abuso de poder e outras formas de comportamento inapropriado (Domingos, 2015; IFAC \&CIPFA, 2014; IIA, 2012; Morais \& Martins, 2013).

\section{FIGURA 6 CONTRIBUTO DOS OBJETIVOS DA AUDITORIA INTERNA PARA RESPONSABILIZAÇÃO DOS ÓRGÃOS DE GESTÃO}

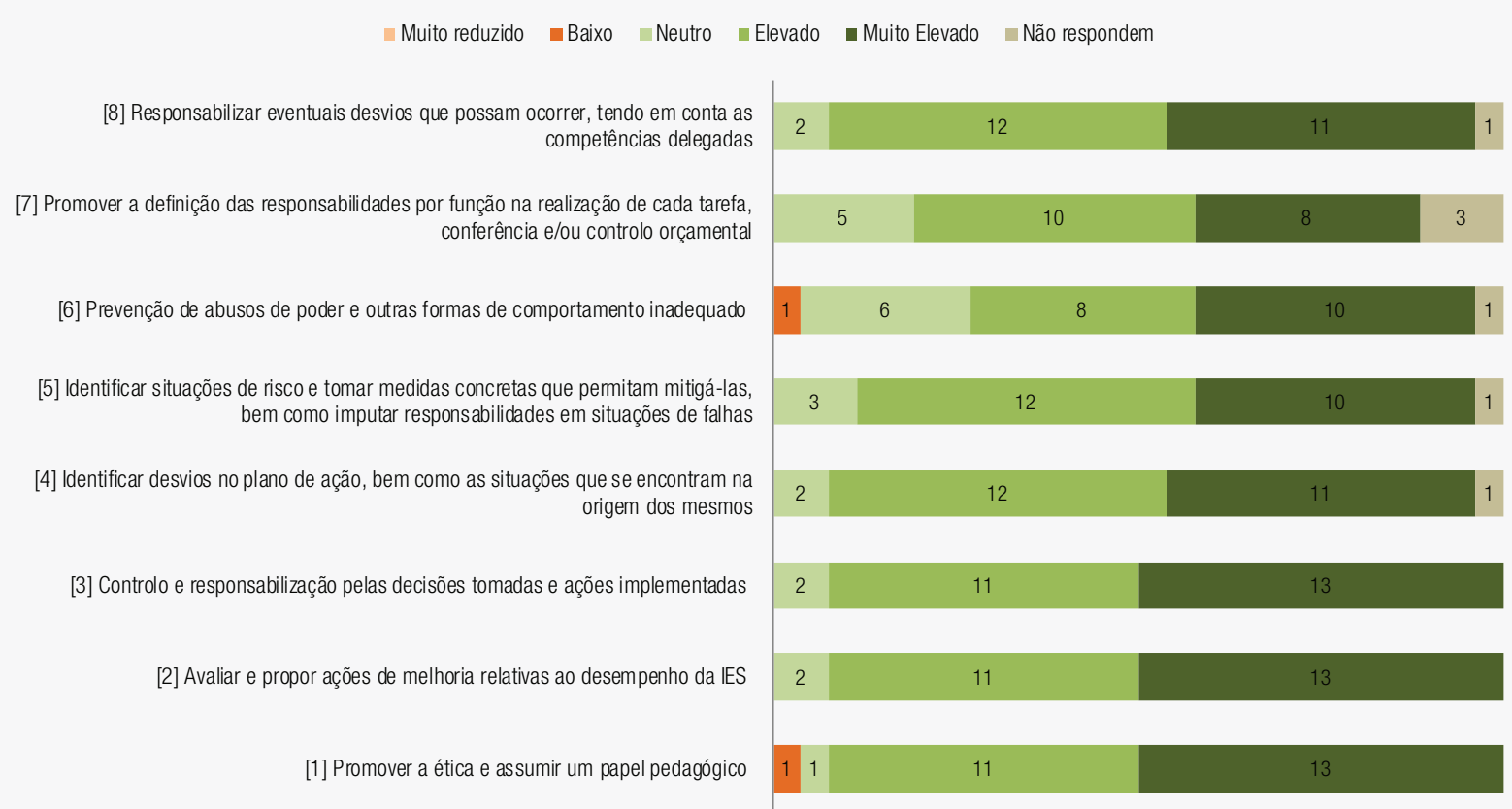

Fonte: Elaborada pelos autores.

Relativamente à última premissa em análise, na Figura 6, observa-se que a todos os itens apresentados é atribuída uma importância elevada ou muito elevada (níveis 4 e 5 da escala), no mínimo por $69 \%$ das IES, com o valor mais baixo a verificar-se nos objetivos 6 e 7 . Relativamente a estes últimos, é-lhes atribuída uma importância neutra na responsabilização (nível 3 da escala) por $23 \%$ e $19 \%$ das entidades respondentes, respectivamente. Por sua vez, a avaliação e a proposta de ações de melhoria relativas ao desempenho (objetivo 2) e o controlo e a responsabilização pelas decisões tomadas e ações implementadas (objetivo 3) são considerados por $92 \%$ das entidades como tendo uma importância elevada ou muito elevada. No sentido contrário, existe apenas uma entidade que atribui uma importância baixa (nível 2 da escala) aos itens 1 e 6, salientando-se ainda que a mais baixa taxa de resposta foi obtida no objetivo 7 (promover a definição das responsabilidades por função na realização de cada tarefa, conferência e/ou controlo orçamentário) que ainda assim atingiu $88 \%(n=23)$. Em síntese, verifica-se que o valor médio das respostas varia entre 4,08 e 4,42, correspondendo o primeiro valor ao objetivo 6 e o segundo aos objetivos 2 e 3 . 


\subsection{Recomendações da auditoria interna e a accountability}

Para que a auditoria interna contribua com os princípios da accountability já mencionados, tornase essencial para as organizações certificar-se de que as recomendações da auditoria interna sejam realizadas, para que haja impacto na tomada de decisão. Por esse motivo, sistemas de controle e monitoramento das recomendações por parte do grupo auditor devem ser implementados.

Com o propósito de avaliar quais são os mecanismos mais utilizados, as seguintes opções foram apresentadas aos participantes da pesquisa: auditorias consecutivas; indicadores relacionados ao grau de realização das recomendações e preparação dos procedimentos e das normas internas.

A Figura 7 mostra que $81 \%$ das IES $(n=21)$ responderam, das quais $85,7 \%(n=18)$ concordam ou concordam totalmente (níveis 4 e 5 da escala) com a implementação dos três mecanismos sugeridos. A preparação de procedimentos e de normas internas é o mecanismo com o maior número de respostas no nível 5 (40\% das IES), especialmente pelos institutos politécnicos. Aquelas instituições que não responderam $(n=5)$, bem como os institutos que discordaram da implementação dos mecanismos não tinham departamentos de auditoria interna em sua estrutura organizacional.

\section{FIGURA 7 MECANISMOS DE CONTROLE E MONITORAMENTO DAS RECOMENDAÇÕES DE AUDITORIA INTERNA}
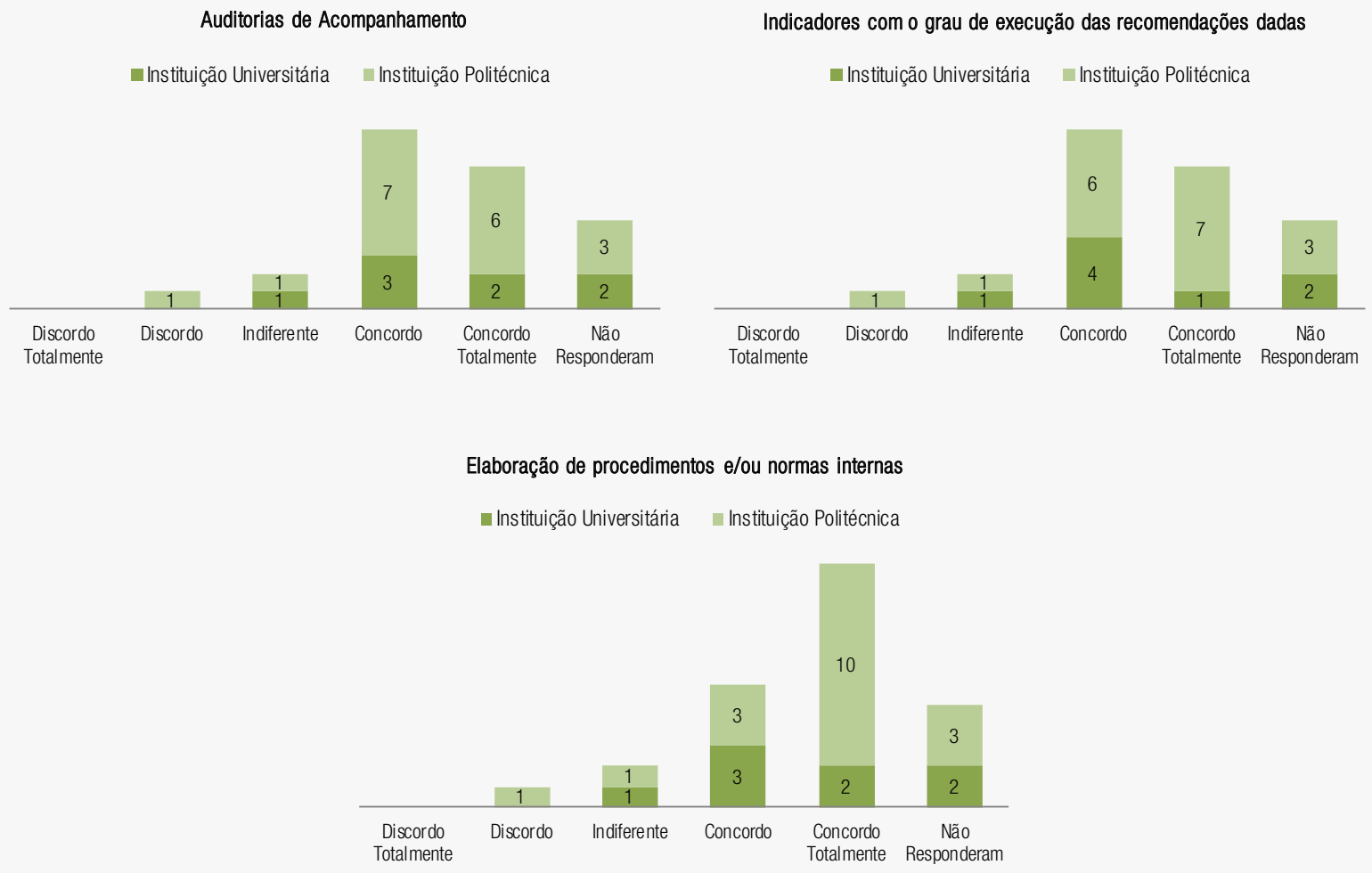

Fonte: Elaborada pelos autores. 
A premissa de que a auditoria interna é uma das bases da boa governança no setor público (IFAC \& CIPFA, 2014) torna-se importante para compreender qual é o ponto de partida de uma IES em relação às recomendações de auditores internos para promover e reforçar os princípios da accountability.

Em seguida, com o intuito de avaliar as contribuições da auditoria interna no processo de tomada de decisão, os grupos gestores das IES responderam em que medida os resultados das auditorias internas (relatórios, opiniões, memorandos, etc.) poderiam afetar na tomada de decisão (novamente utilizando a escala Likert nível 5). Os respondentes das universidades $(\mathrm{n}=7)$ concordam totalmente que as informações influenciam a tomada de decisão (níveis de concordância de 4 e 5, em 57,1\% e $42,9 \%$ dos casos, respectivamente). Quanto aos institutos politécnicos $(\mathrm{n}=18), 11,1 \%$ consideram essa relação indiferente, enquanto os outros concordam $(22,2 \%)$ ou concordam totalmente $(66,7 \%)$. Esses resultados vão ao encontro com as conclusões de Teixeira (2006), evidenciando que as informações fornecidas pela auditoria interna contribuem para a melhoria da eficácia da gestão e ajuda na tomada de decisão. É importante notar que 93\% das IES que concordam ou concordam totalmente com as contribuições que as informações da auditoria interna trazem para a tomada de decisões possuem um setor ou um departamento de auditoria interna em seu organograma.

Além disso, como mostra a Figura 8, os grupos gestores das universidades concordam ou concordam totalmente que a implementação das recomendações das auditorias internas: reforça o controle da avaliação do uso de recursos públicos considerando os princípios dos 3E's e promove a responsabilidade. Apesar de $92 \%$ das respostas $(n=17)$ dos institutos politécnicos se igualam às das universidades (concordam ou concordam totalmente), há duas entidades que discordam ou consideram-se indiferentes às recomendações da auditoria interna.

\section{FIGURA 8 CONTRIBUIÇÕES DAS RECOMENDAÇÕES DA AUDITORIA INTERNA}
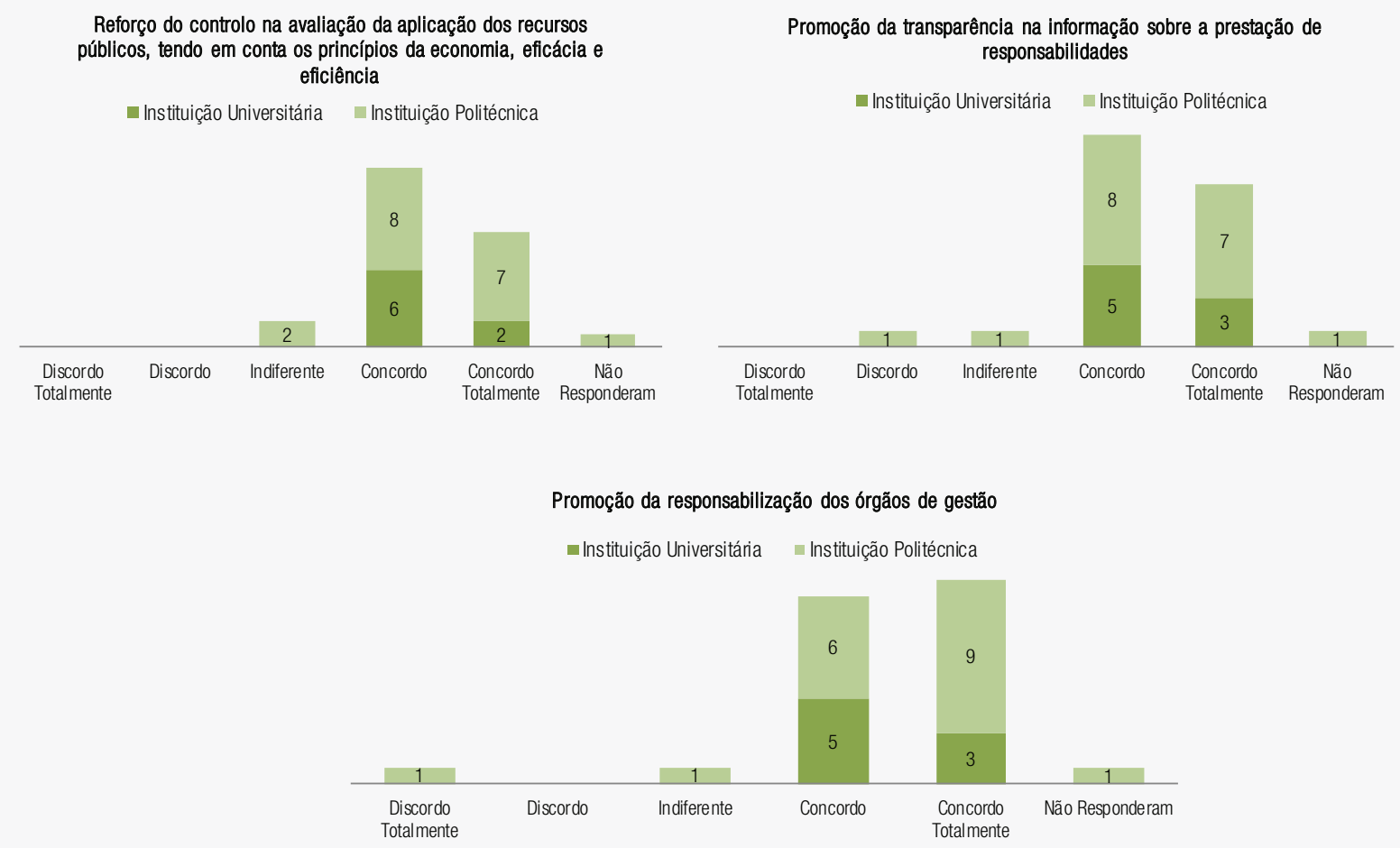

Fonte: Elaborada pelos autores. 


\section{CONCLUSÕES}

Auditar é um dos principais pilares da boa governança no setor público e tem grande efeito na accountability. A obrigação de prestar contas sobre a gestão dos recursos públicos, considerando o interesse público, deve ser realizada de forma transparente, permitindo a responsabilização por meio dos resultados alcançados. $\mathrm{O}$ auditor interno, dessa forma, assume um papel preponderante em delegar responsabilidade e monitorar os objetivos estratégicos, em apoiar a tomada de decisão, em controlar e prevenir abusos de poder e em identificar situações de risco, fraude ou erro (Domingos, 2015; IIA, 2012).

Entretanto, por causa da existência de uma completa relação entre auditoria e accountability na boa governança, ainda há um longo caminho a ser percorrido no setor público, em decorrência da diversidade de implementação das reformas ocorridas em vários países e instituições. Com efeito, essas reformas em muitas jurisdições se concentraram nas informações financeiras, deixando para segundo plano os métodos e as práticas adequadas para a promoção uma accountability de forma integral, permitindo a avaliação de desempenho em conformidade com os 3E's (Carvalho, 2009; IIA, 2012).

Considerando as IES, particularmente no contexto português, as reformas recentes têm sido as seguintes: reforçar a autonomia com comprometimento na prestação de contas; estreitar a relação entre finanças e resultados alcançados; parcerias com diferentes agentes; e internacionalizar e diversificar as fontes de financiamento. À medida que a gestão das IES se aproximou da gestão das organizações privadas, a necessidade de auditoria (interna e/ou externa) e de monitoramento de desempenho surgiu (Santiago \& Carvalho, 2008; Silva, 2016), tanto que a obrigação de prestação de contas de forma transparente, precisa e acessível tornou-se um requisito essencial para promover a accountability (Semyonov \& Platanova, 2017). Com isso, a auditoria interna expandiu seu papel, assegurando a verificação dos 3E's e avaliando o desempenho da gestão das organizações, bem como os riscos, tornando-se, assim, um suporte importante para os órgãos gestores, reforçando o controle e a confiança inerentes às suas funções.

Este trabalho analisou, então, o papel da auditoria interna na promoção da accountability nas IES, tendo como ponto de partida os órgãos de gestão, aplicando uma pesquisa nas instituições públicas portuguesas. $\mathrm{Na}$ amostra, há relativamente menos universidades do que institutos politécnicos, sendo que estes últimos mostraram respostas mais dispersas e mais pessimismo quanto à relação entre auditoria interna e accountability.

O tipo de auditoria que ainda prevalece é a auditoria financeira, realizada por quase todas as instituições, seguido da auditoria de projetos e programas. Esse resultado está alinhado com a análise de Carvalho (2009), segundo o qual a prevalência destas auditorias poderá ter origem nas imposições legais existentes.

No que respeita ao controlo exercido pelo TC, verifica-se que pouco mais de $50 \%$ das instituições de ensino respondentes foram alvo de auditorias externas nos últimos 5 anos, o que denota a inexistência de uma fiscalização externa plena. Quanto às auditorias internas, há um setor ou departamento próprio na estrutura organizacional de quase $60 \%$ dos participantes, hierarquicamente dependente, na maioria dos casos, da reitoria ou presidência. Por isso, as funções da auditoria interna são consideradas no mais alto nível da instituição.

Tendo em consideração a importância crescente da auditoria interna na boa governança e o papel da mesma na promoção dos pilares da accountability, destacam-se a seguir as conclusões das 
questões formuladas com vista a detetar a perceção dos órgãos de gestão das IES sobre esta relação.

No que respeita ao papel da auditoria interna, apresentou-se um conjunto de afirmações às quais, em média, foi atribuído um grau de concordância elevado ou muito elevado, verificando-se uma evolução no sentido em que este tipo de auditoria já não se limita a examinar a legalidade e a conformidade das operações realizadas, não obstante as auditorias de conformidade continuarem a assumir uma maior predominância.

Quanto ao papel da auditoria interna como ferramenta de promoção da accountability, três principais pilares foram considerados. Primeiramente, considerando a auditoria como ferramenta para avaliar o uso de recursos públicos (desempenho), as IES atribuem uma importância elevada e muito elevada à avaliação do grau de execução do plano de ação e dos eventuais desvios que possam existir na aplicação dos recursos públicos. Quanto à transparência na prestação de contas, o item considerado mais importante diz respeito a assegurar o cumprimento da legislação existente. Uma vez que a melhoria da imagem da IES perante os stakeholders foi a vertente com maior número de respostas neutras, pode inferir-se que a informação constante nos relatórios de auditoria interna tem como principais destinatários os órgãos de gestão e serviços auditados, sendo dessa forma limitado o seu campo de atuação na promoção da transparência. Por último, o terceiro pilar da promoção da responsabilidade, as IES conferem uma importância elevada ou muito elevada às vertentes de avaliação e proposta de ações de melhoria relativas ao desempenho e controlo, assim como à responsabilização pelas decisões tomadas e ações implementadas.

Os órgãos de gestão consideram que a informação disponibilizada no âmbito das auditorias internas contribui para a melhoria da eficácia da gestão e auxilia na tomada de decisão. Contudo, para que esta informação surta os efeitos desejados, é necessário proceder à implementação de sistemas de controlo e monitorização das recomendações apresentadas, com a implementação de auditorias de acompanhamento, bem como com a definição de indicadores sobre o grau de execução das recomendações dadas. Já no que respeita ao posicionamentodestas instituições sobre o contributo das recomendações emanadas pelos auditores internos com vista à promoção dos princípios subjacentes à accountability, há uma aceitação geral.

À luz das principais conclusões obtidas com o trabalho em apreço, existem assim condições para reiterar a afirmação inicial de que a auditoria serve a accountability, na medida em que promove os princípios subjacentes a este conceito multifacetado. Consequentemente, as IES que desejam criar um departamento de auditoria interna ou melhorar o papel da que já existe, devem considerar que o desenvolvimento das atividades desse departamento necessita ser um instrumento para apoiar a accountability e a boa governança da organização.

Decidir pelas percepções dos grupos gestores das IES pode ser uma limitação deste estudo, porque ele não captura o impacto da implementação da auditoria interna na promoção da accountability. No entanto, avaliar a percepção/reflexão da gestão sobre a contribuição da auditoria interna para os três pilares da accountability permanece relevante como um passo à frente para a sua implementação. 


\section{REFERÊNCIAS}

Afonso, A. J. (2009, maio/ago.). Políticas avaliativas e accountability em educação - subsídios para um debate Iberoamericano. SÍSIFO - Revista de Ciências da Educação, 9, 57-70.

Bovens, M. (2005). Public accountability. In E. Ferlie, L. E. Lynn, Jr., \& P. Christopher. (Eds.). The Oxford Handbook of Public Management (pp. 182-208). Oxford, UK: Oxford University Press.

Bovens, M. (2006). Analysing and assessing public accountability. A conceptual framework. European Governance Papers - EUROGOV. (C-06-01).

Cameron, W. (2004). Public accountability: effectiveness, equity, ethics. Australian Journal of Public Administration, 63(4), 59-67.

Campos, A. M. (1990). Accountability: quando poderemos traduzi-la para o português? Revista de Administração Pública, 24(2), 30-50.

Carvalho, A. C. (2009). O papel da informação e do controlo externo no processo de accountability: o caso dos municípios portugueses (Tese de doutorado). University of Vigo, Spain.

Montenegro, T. M., \& Celente, A. L. I. (2016). The public sector auditing as an accounting instrument A case study in the Brazilian Navy. Journal of business and projects, $7(3), 29-47$.

Christopher, J. (2012). The adoption of internal audit as a governance control mechanism in Australian public universities - views from the CEOs. Journal of Higher Education Policy and Management, 34(5), 529-541.

Costa, A. F., Pereira, J. M., \& Blanco, S. R. (2006). Auditoria do sector público no contexto da nova gestão pública. Revista de Estudos Politécnicos, III (5/6), 201-225.

Costa, C. B. (2010) Auditoria financeira: teoria e prática (9. Ed.). Lisboa, Portugal: Editora Rei dos Livros.

Crepaldi, S. A. (2016). Auditoria contábil: teoria e prática. (10. Ed.). São Paulo, SP: Atlas.

Dias, C. B., \& Sarrico, C. (2008). Controlo público dos governos municipais: novos horizontes. economia global e gestão, 13(3), 99-118.
Domingos, C. (2015). Auditoria, contabilidade e controle interno no setor público. (7. Ed.). São Paulo, SP: Atlas.

Gomes, P. S., Fernandes, M. J., \& Carvalho, J. B. (2015, setembro). O processo de harmonização internacional da contabilidade pública em Portugal: A perspetiva de diferentes stakeholders. In Proceedings from Congresso dos TOC 20 anos: Uma ambição, um compromisso, um rumo (pp.1-31), Lisboa, Portugal.

Gonçalves, C. M. (2011). A accountability nos serviços autónomos (Dissertação de mestrado). ISCAL, Lisboa, Portugal.

Guri-Rosenblit, S., \& Sebkova, H. (2004). Diversification of higher education systems: patterns, trends and impacts, in Diversification of higher education and the changing role of knowledge and research. (pp. 40-69). Paris, France: UNESCO. (UNESCO Forum Occasional Paper Series, 6).

Hood, C. (1991). A public management for all seasons?, Public administration, 69, 3-19.

Institute of Internal Auditors. (2012). Supplemental guidance: the role of auditing in public sector governance. Flórida, EUA: Author.

International Federation of Accountants \& The Chartered Institute of Public Finance \& Accountancy (2014). International framework: good governance in the public sector. New York, NY: IFAC; CIPFA.

International Federation of Accountants (2014). Handbook of international quality control, auditing, review, other assurance, and related services pronouncements (Vol. I). New York, NY: IFAC.

International Organization of Supreme Audit Institutions (2007). Diretrizes para as normas de controle interno do sector público. Bahia, BA: TCE, 13.

International Organization of Supreme Audit Institutions (2010). ISSAI 20: Principles oftransparency and accountability. Recuperado de https://www.igf. gov.pt/Referenciaisnormasauditoria/Docs_Axs/ Ax3_issai_20_e_.pdf

International Organization of Supreme Audit Institutions (2013). ISSAI 100: Fundamental principles of public-sector auditing. Recuperado de http://www. issai.org/media/69909/issai-100-english.pdf

Kagermann, H., Kinney W., Kutting, K., \& Weber, C.P. (2008). Internal audit handbook. Berlin, German: Springer. 
Leung, P., Cooper, B., \& Perera, L. (2011). Accountability structures and management relationships of internal audit: an Australian study. Managerial Auditing Journal, 26(9), 794-816.

Lindberg, S. (2013). Mapping accountability: core concept and subtypes. International Review of Administrative Sciences, 79(2), 202-226.

Liu, W. B., Cheng, Z. L., Mingers, J., Qi, L., \& Meng, W. (2010). The 3E methodology for developing performance indicators for public sector organizations, Public Money and Management, 30(5), 305-312.

Marçal-Grilo, E. (2003). European higher education society. Tertiary Education and Management, 9(1), $3-11$.

Marques, M. C. (2012). Modelos de governo e gestão universitária: uma visão sobre o contexto atual Português, Revista Iberoamericana de Gestión e Contabilidad, X(19), 1-17.

Marques, M. C. (2014). Os indicadores de gestão nas universidades públicas portuguesas: uma metodologia para análise da sua eficiência (Vol. I). Faro, Portugal: Sílabas \& Desafios.

Marques, M. C., \& Almeida, J. M. (2004). Auditoria no sector público: um instrumento para a melhoria da gestão pública. Revista Contabilidade \& Finanças, 15(35), 84-95.

Martins, P. G. B. (2012). As universidades fundacionais e o new public management (Dissertação de mestrado). University Institute of Lisbon, Lisboa, Portugal.

Morais, G., \& Martins, I. (2013). Auditoria interna - função e processo (4. Ed.). Lisboa, Portugal: Áreas Editora.

Moreira, N. (2014). A Auditoria (forense) e a fraude. In N. Gonçalves, \& C. Pimenta (Eds.), As Facetas da Fraude - Cinco Anos de Crónicas na Visão (pp. 9092). Lisboa, Portugal: V. N. Famalicão.

Mulgan, R. (2000). Accountability: an ever expanding concept? Public administration, 78(3), 555-573.

Nakagawa, M. N., Relvas, T. R., \& Dias, J. M., Filho. (2007). Accountability: A razão de ser da contabilidade. REPEC - Revista de Educação e Pesquisa em Contabilidade, 1(3), 83-100.
Pereira, F. N., Alledi C., Filho, Quelhas, O., Bonina, N., Vieira, J., \& Marques, V. (2017). New public management and new public governance: A conceptual analysis comparison. Espacios, 38(7); 6-30.

Pinheiro, J. L. (2010). Auditoria interna. Lisboa: Rei dos Livros.

Pinho, J. A., \& Sacramento, A. R. (2009). Accountability: já podemos traduzi-la para o português? RAP - Revista de Administração Pública, 43(6), 1343-1368.

Rocha, A. C. (2008, novembro). O Processo orçamentário Brasileiro como instrumento de accountability. In Anais do $3^{\circ} A P G$ - Encontro de Administração Pública e Governança, Salvador, BA, Brasil.

Rocha, A. C. (2009, setembro). Accountability na administração pública: a atuação dos Tribunais de Contas. In Anais do $32^{\circ}$ Encontro da ANPAD, Rio de Janeiro, RJ, Brasil.

Rodrigues, R. C. (2017). A atuação da auditoria interna nas Universidades Federais Brasileiras (Dissertação de mestrado). Universidade Federal do Ceará, Brasil.

Rodrigues, R. C., Machado, M. V. V., \& Sampaio, T. S. L. (2018, July). O perfil da auditoria interna nas Universidades Federais Brasileiras. In Proceedings from $18^{\circ}$ USP International Conference in Accouting.

Sampieri, R. H.; Fernández Collado, C., \& Batista Lucio, M. (2006). Metodologia de pesquisa. São Paulo, SP: McGraw-Hill.

Santiago, R., \& Carvalho, T. (2008). Academics in a new work environment: the impact of NPM on work conditions. Higher Education Quarterly, 62(3), 204-223.

Saraiva, E. M. (2010). A auditoria interna em instituições de ensino superior - o caso do ensino público politécnico (Dissertação de mestrado). Instituto Politécnico de Viseu, Portugal.

Sarrico, C. S. (2010). On performance in higher education: towards performance governance. Tertiary Education and Management, 16(2), 145-158.

Semyonov, D., \& Platanova, D. (2017). Accountability of higher education institutions. Background paper for UNESCO’s Global Education Monitoring Report 
2017/8 'Accountability in education: Meeting our commitments'. Paris, France: UNESCO.

Silva, T. M. C. F. (2016). O impacto da nova gestão pública nas universidades: uma reflexão sobre o normativo brasileiro. In Anais do $16^{\circ}$ Congresso USP de Controladoria e Contabilidade. São Paulo, Brasil.

Speijcken, R., \& Bakker, W. (2011). The elusive quest for the golden standard: Concepts, policies and practices of accountability in development cooperation. Maastricht, the Netherlands: UNUMERIT. (Working Paper Series, 2011-018).
Teixeira, M. F. (2006). O contributo da auditoria interna para uma gestão eficaz (Dissertação de mestrado). Universidade Aberta, Portugal.

Teixeira, V. M. (2012). Impacto da auditoria interna na externa: ótica do auditor externo (Dissertação de Mestrado). Universidade de Aveiro, Portugal.

Tribunal de Contas (1999). Manual de auditoria e procedimentos - Volume I. Lisboa, Portugal: TC.

Wall, A., \& Martin, G. (2003). The disclosure of key performance indicators in the public sector. Public Management Review, 5(4), 491-509.

\section{Anabela dos Reis Fonseca}

https://orcid.org/0000-0001-5075-0932

Auditora Interna na Universidade de Coimbra, Portugal; MSc em Contabilidade e Finanças, Faculdade de Economia na Universidade de Coimbra, Portugal; Pós-Graduada em Finança Coorporativa e Criação de Valor no Instituto Universitário de Lisboa (ISCTE), Portugal. E-mail: ab.barbosa74@gmail.com

\section{Susana Jorge}

https://orcid.org/0000-0003-4850-2387

Professora Auxiliar com Agregação na Faculdade de Economia na Universidade de Coimbra, Portugal; Pesquisadora afiliada do Centro de Investigação em Ciência Política (CICP) na Universidade do Minho, Portugal; PhD em Contabilidade e Finanças, Local Government Accounting (Contabilidade de Governos Locais) na Universidade de Birmingham, UK. E-mail: susjor@fe.uc.pt

\section{Caio Felipe Fonseca do Nascimento}

https://orcid.org/0000-0001-6943-3902

Professor Assistente no Instituto Federal de Educação, Ciência e Tecnologia de Roraima, Brasil; Diretor de Administração e Planejamento no Instituto Federal de Educação, Ciência e Tecnologia de Roraima, Brasil; MSc em Contabilidade e Finanças da Faculdade de Economia na Universidade de Coimbra, Portugal; Especialista em Auditoria na Faculdade Educacional da Lapa, Brasil. E-mail: caio.nascimento@ifrr.edu.br 